\title{
Cancer incidence among pesticide applicators exposed to butylate in the agricultural health study (AHS)
}

\author{
Shannon M. Lynch ${ }^{1}$, Rajeev Mahajan², Laura E. Beane Freeman², Jane A. Hoppin ${ }^{3}$, and \\ Michael C.R. Alavanja ${ }^{2,}$ \\ ${ }^{1}$ Office of the Associate Director, Epidemiology and Genetics Research Program, Division of \\ Cancer Control and Population Sciences, National Cancer Institute, National Institutes of Health, \\ Department of Health and Human Services, Rockville, MD \\ ${ }^{2}$ Occupational and Environmental Epidemiology Branch, Division of Cancer Epidemiology and \\ Genetics, National Cancer Institute, National Institutes of Health, Department of Health and \\ Human Services, Rockville, MD
}

${ }^{3}$ Epidemiology Branch, National Institute of Environmental Health Sciences, National Institutes of Health, Department of Health and Human Services, Research Triangle Park, NC

\section{Abstract}

Although limited, epidemiologic studies suggest possible associations between butylate use and cancer risk, specifically prostate cancer and non-Hodgkin lymphoma (NHL). We examined butylate use and cancer risk more broadly in the AHS, a cohort of licensed pesticide applicators in Iowa and North Carolina. Pesticide use information was collected using self-administered questionnaires. Poisson regression was used to calculate rate ratios(RR) and 95\% confidence intervals(CI). Two exposure metrics were used: lifetime exposure days(LD) and intensityweighted lifetime exposure days(IWLD). We used two referent groups: unexposed to butylate and the lowest butylate usage category. This analysis included 19,655 applicators with complete butylate use information; 5,297 applicators were exposed to butylate, making this the largest study of butylate to-date. The mean follow-up time since enrollment was 9 years. Prostate cancer risk was significantly elevated among applicators in the highest LD category in both referent groups (low exposed referent: $\mathrm{RR}_{\mathrm{LD}}=2.09,95 \% \mathrm{CI}=1.27-3.44$ ). We observed a significantly elevated joint effect of prostate cancer family history and high butylate usage across both exposure metrics and both referent groups (low exposed referent: $\mathrm{RR}_{\mathrm{LD}}=2.00,95 \% \mathrm{CI}=1.07-3.74$ ), and a nonsignificant, elevated interaction between butylate use and prostate cancer family history, similar to a previous AHS finding. Statistically significant increased risks and exposure-response trends were seen for all lymphohematopoietic cancers (AL) and NHL for both exposure metrics and referent groups (low exposed referent: $\mathrm{AL}: \mathrm{RR}_{\mathrm{LD}}=2.27,95 \% \mathrm{CI}=1.18-4.37$; $\mathrm{NHL}: \mathrm{RR}_{\mathrm{LD}}=3.44$, $95 \% \mathrm{CI}=1.29-9.21)$. Our analysis did not find meaningful associations for other cancers analyzed. Further study is warranted for AL, NHL and prostate cancers.

\footnotetext{
*Correspondence to: Dr. Michael C.R. Alavanja, Occupational and Environmental Epidemiology Branch, Division of Cancer Epidemiology and Genetics, National Cancer Institute, 6120 Executive Blvd. EPS 8000, Rockville, Maryland, 20852. Fax: 301-402-1819 Alavanjm@mail.nih.gov.

This is a PDF file of an unedited manuscript that has been accepted for publication. As a service to our customers we are providing this early version of the manuscript. The manuscript will undergo copyediting, typesetting, and review of the resulting proof before it is published in its final citable form. Please note that during the production process errors may be discovered which could affect the content, and all legal disclaimers that apply to the journal pertain.
} 


\section{Keywords}

butylate; pesticide; cancer; agricultural health study

\section{Introduction}

Butylate, a thiocarbamate herbicide, is used on corn and grassy and broadleaf weeds and nutsedge. Because butylate is highly volatile, applications are immediately incorporated into the soil to maximize effect on weeds [United States Environmental Protection Agency (USEPA), 1993a]. Butylate formulations include emulsifiable concentrates, a granular form, and an encapsulated form (USEPA, 1993b). Given butylate's high volatility, humans are exposed mainly through dermal and respiratory exposure routes (USEPA, 2001).

Butylate was first registered as an herbicide in the United States in 1967 (USEPA, 2001) and is widely used. According to a 1993 report, between 6 and 15 million pounds of butylate are applied annually, treating 2 to $7 \%$ of the field corn grown in the United States (USEPA, 1993b). Although butylate usage and production are expected to decline with the introduction of newer herbicides in the United States (USEPA, 2001), butylate use continues in other countries (e.g. India, Hungary, and Canada) (Pesticide Action Network, 2006).

The current state of knowledge on the health effects of butylate is minimal and inconsistent. Like other thiocarbamate pesticides, neurotoxicity is considered the major toxic effect (USEPA, 1993a). Butylate tested in situ with the Zea mays pollen waxy locus assay was not genotoxic (Plewa et al., 1984). Evidence of mutagenicity was seen in mice given an oral dose of butylate (National Institute of Occupational Health and Safety (NIOSH), 1986) and in mouse lymphoma cells treated with butylate (Janess, 1986), but was not mutagenic in the Ames test performed on Salmonella (USEPA, 1989).

Butylate does not appear to induce malignant tumors in experimental animals, although evaluation of oncogenicity was inadequate in mice due to lack of confirmatory histopathology[USEPA, 2001; California Environmental Protection Agency (CAEPA, 1998)]. Based on these studies and the presumption that butylate is of low toxicity to worker populations (USEPA, 1993b) and the general public, the Environmental Protection Agency classified butylate as a "Group E" carcinogen (evidence of non-carcinogenicity for humans) in a report released in 2001 (USEPA, 2001).

The epidemiologic evidence linking butylate with cancer, on the other hand, is suggestive, but inconclusive. Several epidemiologic investigations have examined exposure to carbamate pesticides, including butylate, and the risk of cancer. McDuffie et al. (2001), found a nonstatistically significant elevated risk for non-Hodgkin lymphoma (NHL) associated with the use of thiocarbamate pesticides (odds ratio $[\mathrm{OR}]=1.41 ; 95 \%$ confidence interval [CI], 0.62-2.20). Zheng et al.(2001) also observed an elevated risk of NHL among farmers who ever used carbamate herbicides in general $(\mathrm{OR}=1.5 ; 95 \% \mathrm{CI}, 1.1-2.3)$ and butylate specifically $(\mathrm{OR}=1.6 ; 95 \% \mathrm{CI}, 1.0-2.4)$, though only 45 cases and 76 controls were exposed to butylate, and most farmers had not personally applied it. Recent data from the Agricultural Health Study (AHS) found an increased risk of prostate cancer among study participants exposed to butylate with a family history of prostate cancer, but not among those subjects without a family history (Alavanja et al., 2003). Given the limited carcinogenic and epidemiologic information available on cancer in butylate-exposed populations, we examined the association between butylate use and any cancer with 10 or more exposed cases in the AHS, thus conducting the largest study of butylate to-date. 


\section{Methods}

\section{Cohort enrollment and follow-up}

The AHS is a prospective study of 57,310 licensed pesticide applicators and their spouses who live in Iowa and North Carolina (Alavanja et al., 1996) and were recruited between December 1993 and December 1997 from mandatory certification sessions for using EPAdesignated Restricted Use Pesticides (Alavanja et al., 1999). Members of the AHS cohort were matched to cancer registry files in both states for case identification and to state death registries and the National Death Index to ascertain vital status. Incident cancers were identified for the time period from the date of enrollment through December 2004 and were coded according to the International Classification of Diseases for Oncology, 2nd edition (ICD-O-2). Residence information was verified through current address records of the Internal Revenue Service (address information only), motor vehicle registration offices, and pesticide license registries of the state agricultural departments. Observations were censored in the year of death or movement out of either state. The mean length of follow-up as of December 2004 was 9.14 years. All participants provided informed consent, and the protocol was approved by all appropriate institutional review boards (IRBs).

\section{Exposure assessment}

Study participants were asked to complete a self-administered questionnaire at the time of enrollment, which collected comprehensive exposure data on 22 pesticides, information on ever/never use for 28 additional pesticides, and use of personal protective equipment, pesticide application methods, pesticide mixing, equipment repair, lifestyle factors, cancer history, and other demographic factors. For the 28 pesticides with ever/never data from the enrollment questionnaire, including butylate, more comprehensive exposure data were obtained using the take-home questionnaire; therefore, detailed information on butylate was provided on the take-home questionnaire. The questionnaires may be accessed at http:// www.aghealth.org/questionnaires.html.(National Institutes of Health, 2004).

We constructed two cumulative lifetime butylate exposure metrics: lifetime days (LD), defined as years of use $\times$ number of days used per year, and intensity-weighted lifetime exposure days (IWLD), defined as years of use $\times$ number of days used per year $\times$ intensity level. Intensity level, which incorporates factors that modify pesticide exposure, was estimated using questionnaire data from enrollment and measurement data from other published pesticide exposure literature as follows: intensity level $=$ (mixing status + application method + equipment repair status) $\times$ personal protective equipment use (Dosemeci, 2002).

Among exposed applicators, we categorized the LD and IWLD exposure metrics into lowand high-exposure categories, based on the distribution of all cancer cases $(1-25, \geq 26 \mathrm{LD}$ and 1-157, $\geq 158$ IWLD, so that we could have common metrics for all cancers analyzed. Because the number of exposed cases for all cancers and prostate cancer was large, we categorized the exposure metrics into quartiles based on all cancer cases to obtain more distinct exposure-response categories $(1-9,10-25,26-56, \geq 57$ LD, and 1-55, 56-157, $158-$ $351, \geq 352$ IWLD).

\section{Statistical analysis}

Our analysis included 19,655 applicators who completed the take-home questionnaire . Approximately $44 \%$ of applicators with complete information who filled out the enrollment questionnaire $(n=53,927)$, also completed the take-home questionnaire $(n=23,728)$. After accounting for incident cases only, prevalent cancer cases diagnosed prior to enrollment were excluded $(n=1,075)$, as were applicators who did not include detailed information on 
butylate or were missing other confounding variables included in our statistical model ( $n=$ 4073), thus leaving 19,655 applicators for analysis. Because the confounder distribution may differ by use of butylate, we conducted analyses using both the non-exposed and the lowexposed groups as referents. We investigated those cancer sites for which there were 10 or more exposed incident cancer cases. Specifically, we examined cancers of the prostate, lung, colon, melanoma, bladder, leukemia, oral cavity and NHL. We also examined groupings of all cancers combined and all lymphohematopoietic cancers (consisting of NHL, Hodgkin lymphoma, leukemia, and multiple myeloma).

Statistical analyses were conducted in AHS data release version P1REL0612 using SAS version 9.1. Poisson regression was used to estimate rate ratios (RRs) and 95\% confidence intervals while adjusting for the following confounding factors in all of cancer models, age at enrollment (as a continuous variable), sex, race, smoking status, education, and family history of cancer in first-degree relatives (yes/no for specific cancer site). Further adjustment for use of atrazine (sometimes used in combination with butylate(USEPA, 1993b)), and the 5 pesticides most highly correlated with butylate, that is, metribuzin, chlorimuron-ethyl, pendimethalin, aldrin, and ziram, did not affect point estimates by more than $10 \%$ between butylate use and cancers studied in this analysis; therefore, they were not included in the model. Correlated pesticides were determined based on the strength of the correlation coefficient for intensity-weighted lifetime days of exposure between butylate and the other pesticides (highest: $r=0.60$ [metribuzin]; lowest: $r=0.43$ [chlorimuron-ethyl, pendimethalin, aldrin, ziram]). To further investigate certain findings, we made additional adjustments for solvent use, sun exposure, and physical activity based on previously published associations for select cancers (Adami et al., 1999; Ballard-Barbash et al., 1990; Fritschi et al., 2005; Hartge et al., 2006; Kato et al., 2005; Lee et al., 1997; Mehlman, 2006; Rushton et al., 1997). Tests for trend were carried out using the midpoints of each quartile or category entered into the model as a continuous variable; all statistical tests were two-sided. Tests for trend were calculated only when more than one exposure category was analyzed.

We also stratified the risk of prostate cancer by history of prostate cancer among first-degree relatives. To test for effect modification, we created an interaction term by taking the cross product of family history of prostate cancer and the highest lifetime exposure days category, using those subjects with low exposure to butylate as the referent group.

\section{Results}

Table 1 shows the selected characteristics of the study population. Among the 19,655 subjects with complete exposure information, 5,310 who were not missing butylate exposure information or missing other variables included in our statistical model reported ever having used butylate. The cohort was comprised mostly of white, male, private applicators, which reflected the study population demographics. Applicators never exposed to butylate were similar to those in the higher exposed reference groups in terms of smoking and applicator type. However, the two exposed groups were more similar to each other than to the unexposed group in respect to most categories, notably family history of cancer, age, highest attained education, state of residence, and the five most highly correlated pesticides. Based on the observed differences between the nonexposed and either of the two exposed groups, the lowest exposed group appears to be the more appropriate referent group. However, we also present findings using the nonexposed group as the referent to further evaluate consistency of results and to utilize the additional power gained by using the nonexposed group as the referent.

The RRs for selected cancers among butylate-exposed applicators are presented in Table 2. Risk of all cancers combined was not meaningfully associated with either exposure metric 
using the non-exposed group as the reference, though RRs were significantly decreased for those in the lowest butylate exposure category. We found a statistically significant exposureresponse trend $(p=0.01)$ for all cancers combined for $\mathrm{LD}$, resulting in a rate ratio of $\mathrm{RR}_{\mathrm{LD}}$ $=1.70,95 \% \mathrm{CI}=1.20-2.40$ for the highest exposure quartile, using the low exposed as the referent. A slight excess was also observed using the IWLD metric, but the exposureresponse trend was not statistically significant.

Prostate cancer was the most frequent cancer (153 exposed cases). Using both referent groups, butylate $\mathrm{LD}$ was associated with a statistically significant exposure-response trend (nonexposed $p_{\text {trend }}=0.03$; low exposed $\left.p_{\text {trend }}=0.004\right)$ and elevated RRs of $1.44(95 \% \mathrm{CI}=$ 1.04-2.00) and 2.09 (95\% CI, 1.27-3.44) and in the highest exposure quartile using the nonexposed and low exposed referent, respectively. Excess prostate cancer risk was also observed in the highest quartile for IWLD using both referent groups, and while there was a suggestion of trend, the exposure-response trends were not statistically significant.

A statistically significant elevated risk of all lymphohematopoietic (AL) cancers and NHL was observed using both LD and IWLD and for both referent groups, with statistically significant exposure-response trends noted in the nonexposed group ((nonexposed referent [AL: $\mathrm{RR}_{\mathrm{LD}}=1.84,95 \% \mathrm{CI}=1.14-2.97, \mathrm{LD} p_{\text {trend }}=0.01, \mathrm{RR}_{\mathrm{IWLD}}=1.98,95 \% \mathrm{CI}=1.26-$ $\left.3.10, \mathrm{IWLD} p_{\text {trend }}=0.003\right] ;\left[\mathrm{NHL}: \mathrm{RR}_{\mathrm{LD}}=2.94,95 \% \mathrm{CI}=1.49-5.76, \mathrm{RR}_{\mathrm{IWLD}}=2.87\right.$, $95 \% \mathrm{CI}=1.49-5.53 ; \mathrm{LD}$ and IWLD $\left.p_{\text {trend }}=0.002\right]$ ); (low exposed: $\left[\mathrm{AL}: \mathrm{RR}_{\mathrm{LD}}=2.27,95 \%\right.$ $\left.\mathrm{CI}=1.18-4.37, \mathrm{RR}_{\mathrm{IWLD}}=3.02,95 \% \mathrm{CI}=1.52-6.03\right] ;\left[\mathrm{NHL}: \mathrm{RR}_{\mathrm{LD}}=3.44,95 \% \mathrm{CI}=\right.$ $\left.\left.\left.1.29-9.21, \mathrm{RR}_{\mathrm{IWLD}}=3.69,95 \% \mathrm{CI}=1.31-10.38\right]\right)\right)$.. There were a small number of leukemia cases $(n=11)$. For leukemia, RRs were not significantly elevated and tests for trend were not significant for both exposure metrics and both referent groups. There were too few exposed cases to investigate other lymphohematopoietic cancers, including multiple myeloma $(n=7)$ and Hodgkin disease $(n=2)$.

To further investigate the findings with AL and NHL, we adjusted risk estimates for ever exposure to solvents and sunlight using both referent groups. Ever exposure to solvents was defined as ever exposure to gasoline for cleaning hands/equipment outside or during the growing season and/or ever use of other solvents like paint stripper, turpentine, and benzene for cleaning outside or during the growing season, and/or non-farm occupational exposure to solvents or gasoline. Rate ratios remained elevated and statistically significant for AL cancers and NHL for both exposure metrics and both reference groups while adjusting for solvent exposure (low-exposed referent: $\left[\mathrm{AL}: \mathrm{RR}_{\mathrm{LD}}=4.70,95 \% \mathrm{CI}=1.85-11.9, \mathrm{RR}_{\mathrm{IWLD}}=\right.$ $2.53,95 \% \mathrm{CI}=1.11-5.73] ; \mathrm{NHL}: \mathrm{RR}_{\mathrm{LD}}=4.47,95 \% \mathrm{CI}=1.17-17.1, \mathrm{RR}_{\mathrm{IWLD}}=6.42$ (1.37-30.1), but the risks were slightly lower (between 6-14\%) when using the nonexposed referent. When adjusting the baseline analyses for 3 or more hours of sun exposure per day currently or 10 years ago, rate ratios remained elevated and similar to those recorded in Table 2 for all lymphohematopoietic cancers, and NHL (data not shown).

For lung cancer, rate ratios were below 1.00, and exposure-response trends were not statistically significant using nonexposed as the referent. There were nonstatistically significant excess rate ratios observed in both exposure metrics $\left(\mathrm{RR}_{\mathrm{LD}}=1.64 ; 95 \% \mathrm{CI}=\right.$ $\left.0.75-3.61 ; \mathrm{RR}_{\mathrm{IWLD}}=1.38 ; 95 \% \mathrm{CI}=0.63-3.05\right)$ using the low exposed group as the referent. With further stratification by smoking history, rate ratios were null among nonsmokers exposed to butylate and still nonsignificantly increased among those exposed to butylate who had a history of smoking (data not shown). Applicators with the highest exposure to butylate were more similar to the nonexposed referent group on smoking status.

For melanoma, rate ratios were elevated, but not significant for both referent groups for butylate LD (nonexposed: $\mathrm{RR}=1.75,95 \% \mathrm{CI}=0.81-3.78$; low exposed: $\mathrm{RR}=1.51,95 \% \mathrm{CI}$ 
$=0.58-3.92 ;$ ) and IWLD (nonexposed only: $\mathrm{RR}=1.19,95 \% \mathrm{CI}=0.50-2.85$ ), but tests for trends were not significant. Rate ratios decreased for both referent groups, but did not fluctuate by more than $10 \%$ when adjusting for ever/never sunlight exposure based on 3 or more hours of sun exposure per day during growing season in the present or 10 years ago.

For colon cancer, we found a statistically significant decreased risk $(\mathrm{RR}=0.35,95 \% \mathrm{CI}=0.13-$ $0.95)$ and exposure response trend using the nonexposed group as the referent $(\mathrm{p}=0.04)$, but no significant trend using the low exposed group as the referent. For bladder cancer, we found a nonstatistically significant decreased risk and no suggestion of trend using either referent group. For kidney cancer, RRs were essentially null when using the nonexposed referent. Using th low exposed referent, butylate $\mathrm{LD}(\mathrm{RR}=1.47,95 \% \mathrm{CI}=0.45-4.85)$, but not IWLD $(\mathrm{RR}=0.87,95 \% \mathrm{CI}=0.25-2.99)$ was associated with a nonsignificant elevated risk of kidney cancer.. When adjusting for ever exposure to two possible kidney carcinogens in both referent groups, asbestos (Pesch et al., 2000; Sali and Boffetta, 2000) and cadmium (Il'yasova and Schwartz, 2005), rate ratios approached the null. For oral cavity cancer, rates were nonstatistically elevated in both referent groups for $\mathrm{LD}$ (nonexposed only: $\mathrm{RR}=1.15$, 95\% CI $=0.70-4.05$ ) and IWLD (nonexposed: $\mathrm{RR}=1.20,95 \% \mathrm{CI}=0.88-4.12$; low exposed: $\mathrm{RR}$ $=1.41,95 \% \mathrm{CI}=0.41-4.88$;), and tests for trends were not significant. When adjusting this analysis for alcohol use, rates remained the same. Smoking and alcohol use were not significantly associated with oral cavity cancer in our analyses (data not shown).

To further investigate prostate cancer, we stratified by family history of prostate cancer because this was shown to be an important effect modifier in a previous analysis of AHS data (Table 3). Regardless of referent group, a statistically significant elevated risk was seen in the highest exposure categories for those with a prostate cancer family history, and tests for trend were significant (nonexposed: $\mathrm{RR}_{\mathrm{LD}}=1.65,95 \% \mathrm{CI}=1.01-2.77, p=0.04$; $\mathrm{RR}_{\mathrm{IWLD}}=1.01-2.78,95 \% \mathrm{CI}=1.07-3.74, p=0.04$; low exposed: $\mathrm{RR}_{\mathrm{LD}}=1.94,95 \% \mathrm{CI}=$ $\left.1.05-3.60 ; \mathrm{RR}_{\mathrm{IWLD}}=2.00,95 \% \mathrm{CI}=1.07-3.74\right)$. A statistically significant excess rate ratio was also noted for IWLD for those subjects without a family history of prostate cancer $\left(\mathrm{RR}_{\mathrm{IWLD}}=1.52,95 \% \mathrm{CI}=1.06-2.19\right)$, using low exposed as the referent. Although not significant, interaction terms using both referent groups were elevated.

\section{Discussion}

In this study, we examined cumulative lifetime butylate exposure prior to enrollment as a risk factor for incident cancer diagnosed between enrollment and December 2004. In general, we found no statistically significant, consistent associations for lung, leukemia, melanoma, bladder, kidney, and oral cavity cancers, even when adjusting for possible additional confounding factors. However, it should be noted that sample size was small for some cancers. For all cancers, results were inconsistent across referent groups, and the elevated risk in LD seen for those in the higher exposure groups using the low exposed referent was driven primarily by the increased risk of prostate cancer and AL cancers.

We observed a possible association between butylate use and increased prostate cancer risk in our study, particularly for those with a family history of prostate cancer. Previous studies, although not always consistent (Acquavella et al., 1998; Blair et al., 1992), have found the farming occupation,(Fleming et al., 1999; Settimi et al., 2001; Settimi et al., 2003; van der Gulden et al., 1995; Van Maele-Fabry et al.,2003) and particularly pesticide exposure, to be modestly but significantly associated with prostate cancer (Morrison et al., 1993; Settimi et al., 2001, van der Gulden et al., 1995). In our study, the exposure-response association using either the LD or the IWLD generally showed an increased prostate cancer risk with increased exposure, though the IWLD was somewhat attenuated. The biological mechanism 
linking prostate cancer to pesticide use is not well-understood, though the DNA repair pathways have been implicated (Hu et al. 2004).

Patterns generally were consistent and significant across exposure metrics and across referent groups when evaluating the joint effect of family history and the highest category of butylate use on increased prostate cancer risk. Prostate cancer family history is a known risk factor for prostate cancer (Bratt et al., 1999; Spitz et al., 1991). A statistical interaction between butylate use and a family history of prostate cancer was previously observed in the AHS (Alavanja et al., 2003). Although our interaction terms were elevated, they were not significant. This study has the benefit of longer follow-up time, more detailed butylate exposure information, and the ability to control for additional confounders that could affect the interaction.

We observed a consistent, significant association between butylate exposure, AL cancers, and NHL in our analyses, although the number of exposed cases was small for NHL $(n=18)$ and leukemia $(n=11)$. NHL represented almost half of the reported cases of AL cancers. Previous studies have suggested that exposure to carbamates (Cantor et al., 1992; Hoar et al., 1986; McDuffie et al., 2001; Zahm et al., 1988), thiocarbamates (McDuffie et al., 2001), and butylate specifically (Zheng et al., 2001), may be associated with an elevated risk of NHL. However, studies of molecular mechanisms linking butylate to AL cancers have not been conducted, though chromosomal aberrations have been implicated in linking other pesticides to AL cancers (Baccarelli et al . 2006). Previous studies have also found a possible link between solvent exposure and lymphohematopoietic cancers like multiple myeloma (Sonoda et al., 2005), leukemia (Rushston et al., 1997), and NHL (Fritschi et al., 2005; Kato et al., 2005; Mehlman, 2006). When adjusting for ever/never solvent exposure in our analyses, RRs remained elevated and statistically significant for all lymphohematopoietic cancers and NHL. There is conflicting evidence as to whether exposure to sunlight is positively (Adami et al., 1999) or negatively (Hartge et al., 2006) associated with NHL. In our study, sunlight exposure did not significantly affect the observed rate ratios.

In this analysis, a statistically significant decreased colon cancer risk was seen with increasing butylate exposure for IWLD using the nonexposed as the referent, but the association was not statistically significant when the other exposure metrics or referent group were used. Lack of physical activity is suspected to increase colon cancer risk (Ballard-Barbash et al., 1990; Lee et al., 1997). Farmers are generally believed to have lower mortality rates than the general population because they are physically active (Blair et al., 1991; Blair et al., 1992). Approximately $60 \%$ of the applicators in this analysis recorded recreational physical activity of 3-5 hours per week in addition to their physically demanding jobs. When adjusting for physical activity, colon cancer rate ratios were lower.

In this analysis, exposure-response patterns sometimes differed across referent groups and RRs were generally lower for most cancers analyzed when using the nonexposed referent, suggesting that these referent groups may be different due to both identified and unidentified confounding factors among those exposed and unexposed to butylate. With the exception of AL cancers, NHL, and leukemia, RRs were somewhat lower, for the IWLD exposure metric compared to LD. The intensity weighting factor in our exposure metric is designed to help distinguish between exposure days of relatively high exposure from exposure days of relative low exposure. While one would generally expect statistical significance to be more apparent with the more specific exposure metric, i.e., IWLD, some fluctuations of risk estimates may be expected with relatively small samples. When we use the IWLD metric, our sample size reduces slightly from the LD metric, by about $1 \%$ across cancers analyzed, so diminished power did not seriously limit our ability to detect differences in cancer risk. 
Additionally, when reclassifying the applicators using the IWLD metric, some applicators move from a high exposure group to a lower exposure group or vice versa, which could affect point estimates and tests for trend. Additional follow-up data and exposure data from the AHS cohort incorporating changes in specific pesticide use over time should help further clarify our assessment of cancer risk.

The AHS has several important strengths. It is the largest study to date of pesticide applicators exposed to butylate. Because comprehensive questionnaire data were used to estimate butylate exposure, particularly duration and intensity, we were able to provide greater discrimination between potential high and low exposures to butylate. The AHS has information on many potential cancer risk factors and can control for many potential confounders. In general, farmers provided reliable information and considerable detail regarding their pesticide history (Blair et al., 2002; Hoppin et al., 2002), and in a prospective study like the AHS, the effect of recall bias is minimized as cancers were diagnosed after completing the enrollment questionnaire. Although this study was restricted to the $44 \%$ of applicators who completed the supplemental take-home questionnaire, cancer risk was not related to whether applicators did or did not complete the take-home questionnaire, which suggests that collecting information from the take-home questionnaire did not result in selection bias (Tarone et al, 1997).

Certain limitations of our dataset should be recognized including, limited numbers of exposed cancer cases for some analyses, a relatively short period of cancer follow-up, and an exposure assessment that was based primarily on questionnaire data. For example, in a previous analysis, Alavanja et al. 2003 evaluated prostate cancer family history and butylate exposure as ever/never only, using the full cohort $(\mathrm{n}=55,332)$. We limited this analysis to those who completed the take-home questionnaire, which included detailed butylate exposure information $(n=19,655)$ in order to evaluate exposure-response associations adjusted for a number of potentially important confounders. The reduced sample size limited our conclusions about some cancers, particularly the effect modification of butylate exposure with a family history of prostate cancer on prostate cancer risk.

Although the period of cancer incidence follow-up is only 9.14 years on average, the actual time from butylate first use to the end of follow-up is longer. Approximately $90 \%$ of applicators first used butylate before 1980. Since cancer incidence in the AHS cohort was measured from 1994 through 2004 the minimum period of cancer follow-up for most study subjects would be 14 years for those diagnosed with cancer in 1994, and 24 years for those diagnosed with cancer in 2004 , which is a period of time generally thought to encompass the time necessary for the induction of many cancers.

While our exposure assessment was not based on direct measurement of exposure, on every study subject, our IWLD exposure metric is based on questionnaire data that has been shown to be significantly correlated with field measurements of pesticide exposure and should, therefore, generally provide an improved measure of exposure. However, results may vary for individual pesticides (Coble et al. 2005).

With the benefit of a large sample size and detailed exposure information on applicators who personally applied butylate, we observed an association between butylate exposure and all lymphohematopoietic cancers and NHL, which is consistent with previous studies (Cantor et al., 1992; Hoar et al., 1986; McDuffie et al., 2001; Zahm et al., 1988; Zheng et al., 2001). Our findings also suggest a possible association between butylate exposure and prostate cancer incidence and tend to support the previous finding that butylate exposure may be associated with an increased prostate cancer risk in those with a family history of 
prostate cancer. It will be important to reevaluate the associations identified in the AHS as new cases accumulate and to compare these results to those in other studies.

\section{Acknowledgments}

This research was supported by the Intramural Research Program of the National Cancer Institute and National Institute of Environmental Health Sciences, National Institutes of Health.

\section{Abbreviations}

$\begin{array}{ll}\text { AHS } & \text { Agricultural Health Study } \\ \text { AL } & \text { All lymphohematopoietic cancers } \\ \text { CI } & \text { Confidence Intervals } \\ \text { EPA } & \text { Environmental Protection Agency } \\ \text { ICD-O-2- } & \text { International Classification for Disease for Oncology, } 2^{\text {nd }} \text { Edition } \\ \text { IRB } & \text { Institutional Review Board } \\ \text { IWLD } & \text { Intensity-Weighted Lifetime Exposure Day } \\ \text { LD } & \text { Lifetime Days of Exposure } \\ \text { NHL } & \text { Non-Hodgkin Lymphoma } \\ \text { OR } & \text { Odds Ratio } \\ \text { PAN } & \text { Pesticide Action Network } \\ \text { RR } & \text { Rate Ratios } \\ \text { SIR } & \text { Standardized Incidence Ratio }\end{array}$

\section{References}

Acquavella J, Olsen G, Cole P, Ireland B, Kaneene J, Schuman S, Holden L. Cancer among farmers: a meta-analysis. Ann Epidemiol. 1998; 8:64-74. [PubMed: 9465996]

Adami J, Gridley G, Nyrén O, Dosemeci M, Linet M, Glimelius B, Ekbom A, Zahm SH. Sunlight and non-Hodgkin's lymphoma: a population-based cohort study in Sweden. Int J Cancer. 1999; 80:641645. [PubMed: 10048959]

Alavanja MC, Sandler DP, McMaster SB, Zahm SH, McDonnell CJ, Lynch CF, Pennybacker M, Rothman N, Dosemeci M, Bond AE, Blair A. The Agricultural Health Study. Environ Health Perspect. 1996; 104:362-369. [PubMed: 8732939]

Alavanja MC, Sandler DP, McDonnell CJ, Lynch CF, Pennybacker M, Zahm SH, Mage DT, Steen WC, Wintersteen W, Blair A. Characteristics of pesticide use in a pesticide applicator cohort: the Agricultural Health Study. Environ Res. 1999; 80:172-179. [PubMed: 10092410]

Alavanja MC, Samanic C, Dosemeci M, Lubin J, Tarone R, Lynch CF, Knott C, Thomas K, Hoppin JA, Barker J, Coble J, Sandler DP, et al. Use of agricultural pesticides and prostate cancer risk in the Agricultural Health Study cohort. Am J Epidemiol. 2003; 157:800-814. [PubMed: 12727674]

Baccarelli A, Hirt C, Pesatori AC, Consonni D, Patterson DG Jr. Bertazzi PA, Dölken G, Landi MT. $\mathrm{t}(14 ; 18)$ translocations in lymphocytes of healthy dioxin-exposed individuals from Seveso, Italy. Carcinogenesis. 2006; 27(10):2001-2007. Epub 2006 Mar 16. [PubMed: 16543249]

Ballard-Barbash R, Schatzkin A, Albanes D, Schiffman MH, Kreger BE, Kannel WB, Anderson KM, Helsel WE. Physical activity and risk of large bowel cancer in the Framingham Study. Cancer Res. 1990; 50:3610-3613. [PubMed: 2340509]

Blair A, Zahm SH. Cancer among farmers. Occup Med. 1991; 6:335-354. [PubMed: 1835166] 
Blair A, Zahm SH, Pearce NE, Heineman EF, Fraumeni JF Jr. Clues to cancer etiology from studies of farmers. Scand J Work Environ Health. 1992; 18:209-215. [PubMed: 1411362]

Blair A, Tarone R, Sandler D, Lynch CF, Rowland A, Wintersteen W, Steen WC, Samanic C, Dosemeci M, Alavanja MC. Reliability of reporting on life-style and agricultural factors by a sample of participants in the Agricultural Health Study from Iowa. Epidemiology. 2002; 13:94-99. [PubMed: 11805592]

Bratt O, Kristoffersson U, Lundgren R, Olsson H. Familial and hereditary prostate cancer in southern Sweden. A population-based case-control study. Eur J Cancer. 1999; 35:272-277. [PubMed: 10448270]

California Environmental Protection Agency. Summary of toxicological data. Butylate: Feb 27. 1998 Department of Pesticide Regulation. Medical Toxicology Branch. Available at: http:// www.cdpr.ca.gov/docs/toxsums/pdfs/565.pdf [Accessed 21 2008]

Cantor KP, Blair A, Everett G, Gibson R, Burmeister LF, Brown LM, Schuman L, Dick FR. Pesticides and other agricultural risk factors for non-Hodgkin's lymphoma among men in Iowa and Minnesota. Cancer Res. 1992; 52:2447-2455. [PubMed: 1568215]

Coble J, Arbuckle T, Lee W, Alavanja M, Dosemeci M. The validation of a pesticide exposure algorithm using biological monitoring results. J Occup Environ Hyg. 2005; 2(3):194-201. [PubMed: 15764542]

Dosemeci M, Alavanja MC, Rowland AS, Mage D, Zahm SH, Rothman N, Lubin JH, Hoppin JA, Sandler DP, Blair A. A quantitative approach for estimating exposure to pesticides in the Agricultural Health Study. Ann Occup Hyg. 2002; 46:245-260. [PubMed: 12074034]

Fleming LE, Bean JA, Rudolph M, Hamilton K. Cancer incidence in a cohort of licensed pesticide applicators in Florida. J Occup Environ Med. 1999; 41:279-288. [PubMed: 10224594]

Fritschi L, Benke G, Hughes AM, Kricker A, Vajdic CM, Grulich A, Turner J, Milliken S, Kaldor J, Armstrong BK. Risk of non-Hodgkin lymphoma associated with occupational exposure to solvents, metals, organic dusts and PCBs (Australia). Cancer Causes Control. 2005; 16:599-607. [PubMed: 15986116]

Hartge P, Lim U, Freedman DM, Colt JS, Cerhan JR, Cozen W, Severson RK, Davis S. Ultraviolet radiation, dietary vitamin $\mathrm{D}$, and risk of non-Hodgkin lymphoma (United States). Cancer Causes Control. 2006; 17:1045-1052. [PubMed: 16933055]

Hoar SK, Blair A, Holmes FF, Boysen CD, Robel RJ, Hoover R, Fraumeni JF Jr. Agricultural herbicide use and risk of lymphoma and soft-tissue sarcoma. JAMA. 1986; 256:1141-1147. [PubMed: 3801091]

Hoppin JA, Yucel F, Dosemeci M, Sandler DP. Accuracy of self-reported pesticide use duration information from licensed pesticide applicators in the Agricultural Health Study. J Expo Anal Environ Epidemiol. 2002; 12:313-318. [PubMed: 12198579]

Hu JJ, Hall MC, Grossman L, Hedayati M, McCullough DL, Lohman K, Case LD. Deficient nucleotide excision repair capacity enhances human prostate cancer risk. Cancer Res. 2004; 64(3): 1197-1201. [PubMed: 14871857]

Il'yasova D, Schwartz GG. Cadmium and renal cancer. Toxicol Appl Pharmacol. 2005; 207:179-186. [PubMed: 16102569]

Janess, MB. Mutagenicity evaluation in mouse lymphoma multiple endpoint TES, cytogenetic assay. Farmington, Conn: The in vitro toxicology section, environmental health center, Stauffer Chemical Co; Apr. 1986 Report \#T-12686:

Kato I, Koenig KL, Watanabe-Meserve H, Baptiste MS, Lillquist PP, Frizzera G, Burke JS, Moseson M, Shore RE. Personal and occupational exposure to organic solvents and risk of non-Hodgkin's lymphoma (NHL) in women. Cancer Causes Control. 2005; 16:1215-1224. [PubMed: 16215872]

Lee IM, Manson JE, Ajani U, Paffenbarger RS Jr. Hennekens CH, Buring JE. Physical activity and risk of colon cancer: the Physicians' Health Study (United States). Cancer Causes Control. 1997; 8:568-574. [PubMed: 9242472]

McDuffie HH, Pahwa P, McLaughlin JR, Spinelli JJ, Fincham S, Dosman JA, Robson D, Skinnider LF, Choi NW. Non-Hodgkin's lymphoma and specific pesticide exposures in men: cross-Canada study of pesticides and health. Cancer Epidemiol Biomarkers Prev. 2001; 10:1155-1163.

[PubMed: 11700263] 
Mehlman MA. Causal relationship between non-Hodgkin's lymphoma and exposure to benzene and benzene-containing solvents. Ann N Y Acad Sci. 2006; 1076:120-128. [PubMed: 17119197]

Morrison H, Savitz D, Semenciw R, Hulka B, Mao Y, Morison D, Wigle D. Farming and prostate cancer mortality. Am J Epidemiol. 1993; 137:270-280. [PubMed: 8452135]

National Institute for Occupational Safety and Health (NIOSH). Registry of toxic effects of chemical substances (RTECS). Ohio: Cincinnati; 1981-1986.

National Institutes of Health. Agricultural Health Study Homepage. Bethesda, Md: 2004. Available at: http://www.aghealth.org [Accessed: July 21, 2008]

PAN (Pesticide Action Network). [Accessed: July 21, 2008] Pesticide action database-regulation. 2006. Available at:http://www.pesticideinfo.org/Detail_ChemReg.jsp?Rec_Id=PC33220

Pesch B, Haerting J, Ranft U, Klimpel A, Oelschlägel B, Schill W. Occupational risk factors for renal cell carcinoma: agent-specific results from a case-control study in Germany. MURC Study Group. Multicenter urothelial and renal cancer study. Int J Epidemiol. 2000; 29:1014-1024. [PubMed: $11101542]$

Plewa MJ, Wagner ED, Gentile GJ, Gentile JM. An evaluation of the genotoxic properties of herbicides following plant and animal activation. Mutat Res. 1984; 136:233-245. [PubMed: 6377060]

Rushton L, Romaniuk H. A case-control study to investigate the risk of leukemia associated with exposure to benzene in petroleum marketing and distribution workers in the United Kingdom. Occup Environ Med. 1997; 54:152-166. [PubMed: 9155776]

Sali D, Boffetta P. Kidney cancer and occupational exposure to asbestos: a meta-analysis of occupational cohort studies. Cancer Causes Control. 2000; 11:37-47. [PubMed: 10680728]

Settimi L, Comba P, Bosia S, Ciapini C, Desideri E, Fedi A, Perazzo PL, Axelson O. Cancer risk among male farmers: a multi-site case-control study. Int J Occup Med Environ Health. 2001; 14:339-347. [PubMed: 11885917]

Settimi L, Masina A, Andrion A, Axelson O. Prostate cancer and exposure to pesticides in agricultural settings. Int J Cancer. 2003; 104:458-461. [PubMed: 12584743]

Sonoda T, Ishida T, Mori M, Sakai H, Noguchi M, Mori M, Imai K. A case-control study of multiple myeloma in Japan: association with occupational factors. Asian Pac J Cancer Prev. 2005; 6:33-36. [PubMed: 15780029]

Spitz MR, Currier RD, Fueger JJ, Babaian RJ, Newell GR. Familial patterns of prostate cancer: a casecontrol analysis. J Urol. 1991; 146:1305-1307. [PubMed: 1942282]

Tarone RE, Alavanja MC, Zahm SH, Lubin JH, Sandler DP, McMaster SB, Rothman N, Blair A. The Agricultural Health Study: factors affecting completion and return of self-administered questionnaires in a large prospective cohort study of pesticide applicators. Am J Ind Med. 1997; 31:233-242. [PubMed: 9028440]

US Environmental Protection Agency. Butylate: Health advisory. Washington, DC: Office of Drinking Water; 1989.

US Environmental Protection Agency. Butylate (Sutan): Summary. 1993a. Available at: http:// www.epa.gov/IRIS/subst/0215.htm

Butylate, RED. US Environmental Protection Agency. [Accessed: July 21, 2008] Extension toxicology network (EXTOXNET). Butylate pesticide information profile. 1993b. fact sheet; Available at: http://pmep.cce.cornell.edu/profiles/extoxnet/24d-captan/butylate-ext.html

US Environmental Protection Agency. Butylate: Notice of pesticide report on FQPA tolerance reassessment progress and interim risk management decision. US Federal Register. Sep.2001 66(176) Available at: http://www.epa.gov/EPA-PEST/2001/September/Day-11/p22754.htm.

van der Gulden JW, Kolk JJ, Verbeek AL. Work environment and prostate cancer risk. Prostate. 1995; 27:250-257. [PubMed: 7479392]

Van Maele-Fabry G, Willems JL. Occupation related pesticide exposure and cancer of the prostate: a meta-analysis. Occup Environ Med. 2003; 60:634-642. [PubMed: 12937183]

Zheng T, Zahm SH, Cantor KP, Weisenburger DD, Zhang Y, Blair A. Agricultural exposure to carbamate pesticides and risk of non-Hodgkin lymphoma. J Occup Environ Med. 2001; 43:641649. [PubMed: 11464396] 
Zahm SH, Weisenburger DD, Babbitt PA, Saal RC, Vaught JB, Cantor KP, Blair A. A case-control study of non-Hodgkin's lymphoma and agricultural factors in Eastern Nebraska. Am J Epidemiol. $1988 ; 128: 901$. 
TABLE 1

Selected Characteristics of Applicators by Butylate Exposure in the Agricultural Health Study Based on 19931997 Enrollment Data

\begin{tabular}{|c|c|c|c|}
\hline Characteristics & $\begin{array}{r}\text { Non-exposed group, } \\
\text { No. }(\%) \\
(n=14368)\end{array}$ & $\begin{array}{r}\text { Lowest exposed } \\
\text { quartile, No. }(\%) \\
(n=1668)^{I}\end{array}$ & $\begin{array}{r}\text { Highest } 3 \text { quartiles } \\
\text { combined, No. }(\%) \\
(n=3629)^{2}\end{array}$ \\
\hline \multicolumn{4}{|l|}{ Age } \\
\hline$<40$ & 4538 (31.6) & $359(21.5)$ & $848(23.4)$ \\
\hline $40-49$ & $3716(25.9)$ & $526(31.5)$ & $1309(36.0)$ \\
\hline $50-59$ & $3036(21.1)$ & $444(26.6)$ & $884(24.4)$ \\
\hline$\lcm{60}$ & 3078 (21.4) & $339(20.4)$ & $588(16.2)$ \\
\hline \multicolumn{4}{|l|}{ Sex } \\
\hline Male & $13848(96.3)$ & $1654(99.2)$ & 3608 (99.4) \\
\hline Female & $520(3.7)$ & $14(0.84)$ & $21(0.58)$ \\
\hline \multicolumn{4}{|l|}{ Race } \\
\hline White & 14165 (98.6) & $1661(99.6)$ & 3606 (99.4) \\
\hline Non-white & $203(1.4)$ & $7 \quad(0.40)$ & $23(0.63)$ \\
\hline \multicolumn{4}{|l|}{ State of residence } \\
\hline Iowa & $9612(66.9)$ & $1388(83.2)$ & $3116(85.9)$ \\
\hline North Carolina & $4756(33.1)$ & $280(16.8)$ & $513(14.1)$ \\
\hline \multicolumn{4}{|l|}{ Applicator type ${ }^{3}$} \\
\hline Private & $12756(88.9)$ & $1606(96.3)$ & 3147 (86.7) \\
\hline Commercial & $1612(11.1)$ & $62(3.7)$ & $482(13.3)$ \\
\hline \multicolumn{4}{|l|}{ Smoking history } \\
\hline Never & $8072(56.1)$ & $985(59.1)$ & $1994(55.0)$ \\
\hline Low (<12 pack-years) & $3121(21.7)$ & $352(21.1)$ & $844(23.2)$ \\
\hline High ( $\geq 12$ pack-years) & $3175(22.2)$ & $331(19.8)$ & $791(21.8)$ \\
\hline \multicolumn{4}{|l|}{ Alcohol consumption } \\
\hline No & $5060(35.2)$ & $466(27.9)$ & $897(24.7)$ \\
\hline Yes & $9308(64.8)$ & $1202(72.1)$ & $2732(75.3)$ \\
\hline $\begin{array}{l}\text { Educational level } \\
\text { High school/GED or lower }\end{array}$ & $8098(56.4)$ & $856(51.3)$ & $1752(48.3)$ \\
\hline Beyond high school & $6270(43.6)$ & $812(48.7)$ & $1877(51.7)$ \\
\hline \multicolumn{4}{|l|}{ Family history of cancer 4} \\
\hline No & $8150(56.7)$ & $886(53.1)$ & 1908 (52.6) \\
\hline Yes & $6218(43.3)$ & $782(46.9)$ & $1721(47.4)$ \\
\hline \multicolumn{4}{|c|}{$\begin{array}{l}\text { Ever exposure to } 5 \text { most highly } \\
\text { correlated with butylate }\end{array}$} \\
\hline Metribuzin & $3933(26.2)^{5}$ & $1099(65.9)^{6}$ & $2695(74.3)^{7}$ \\
\hline Chlorimuron-ethyl & $4047(26.9)^{5}$ & $751(45.0)^{6}$ & $1866(51.4)^{7}$ \\
\hline Pendimethalin & $23_{5} 4771(31.7)$ & $808(48.4)^{6}$ & $2146(59.1)^{7}$ \\
\hline Aldrin & $1697(11.3)^{5}$ & $437(26.2)^{6}$ & $1027(28.3)^{7}$ \\
\hline Ziram & $65(0.4)^{5}$ & $8(0.5)^{6}$ & $19(0.5)^{7}$ \\
\hline
\end{tabular}


${ }^{1}$ First quartile of lifetime days of exposure (years of use $x$ days of use per year).

${ }^{2}$ Second, third and fourth quartile of lifetime days of exposure (years of use $\mathrm{X}$ days of use per year).

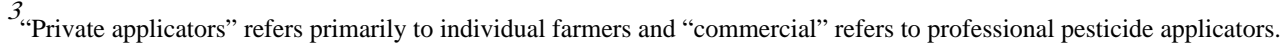

${ }^{4}$ Cancer history refers to first degree relatives.

5 Ever exposed to indicated chemical but not to butylate (thus, numbers in columns do not sum to $100 \%$ ).

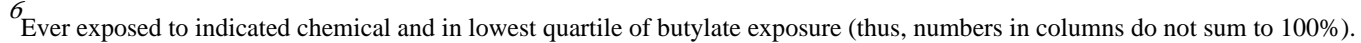

${ }^{7}$ Ever exposed to indicated chemical and in the highest three quartiles of butylate exposure (thus, numbers in columns do not sum to $100 \%$ ). 


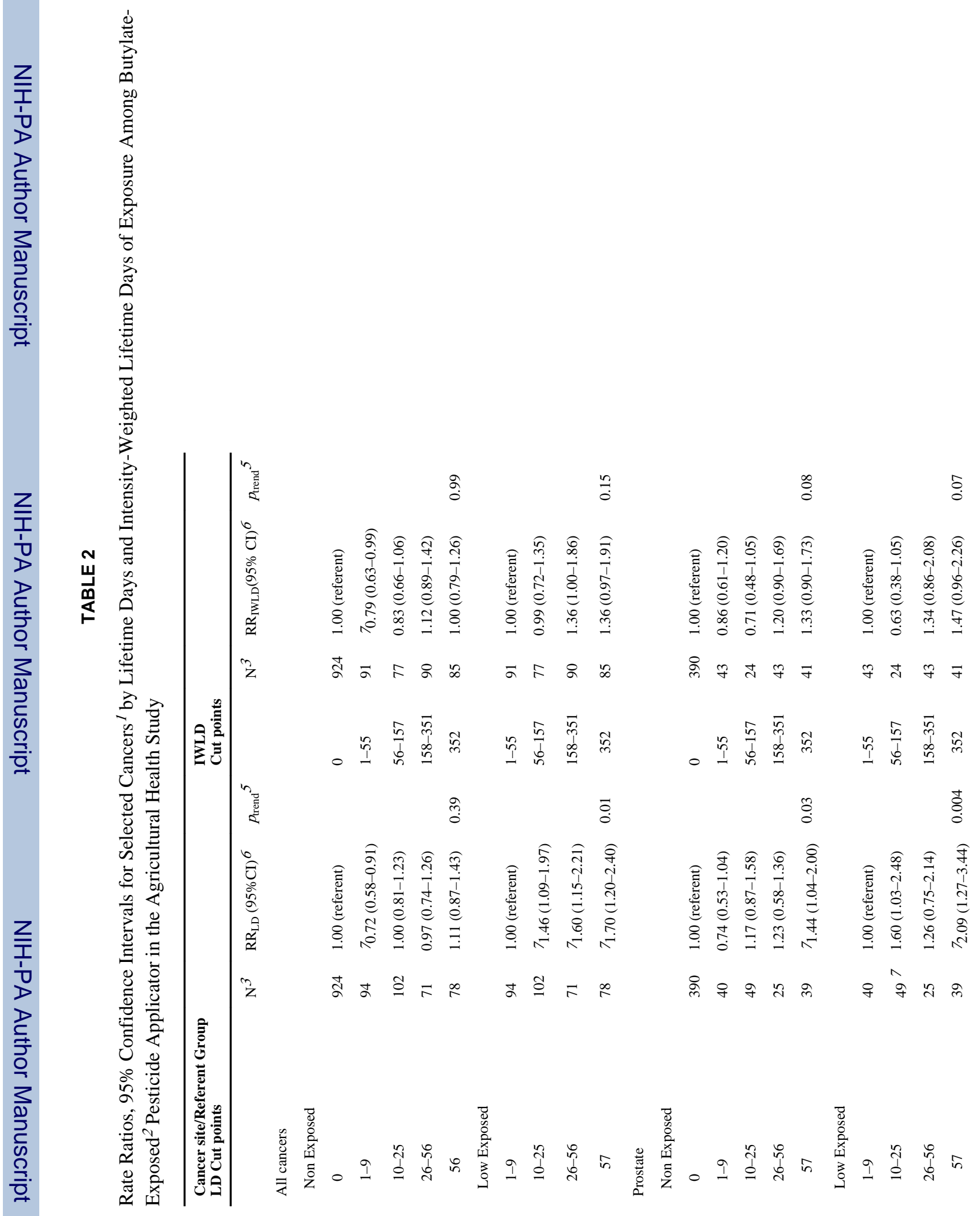




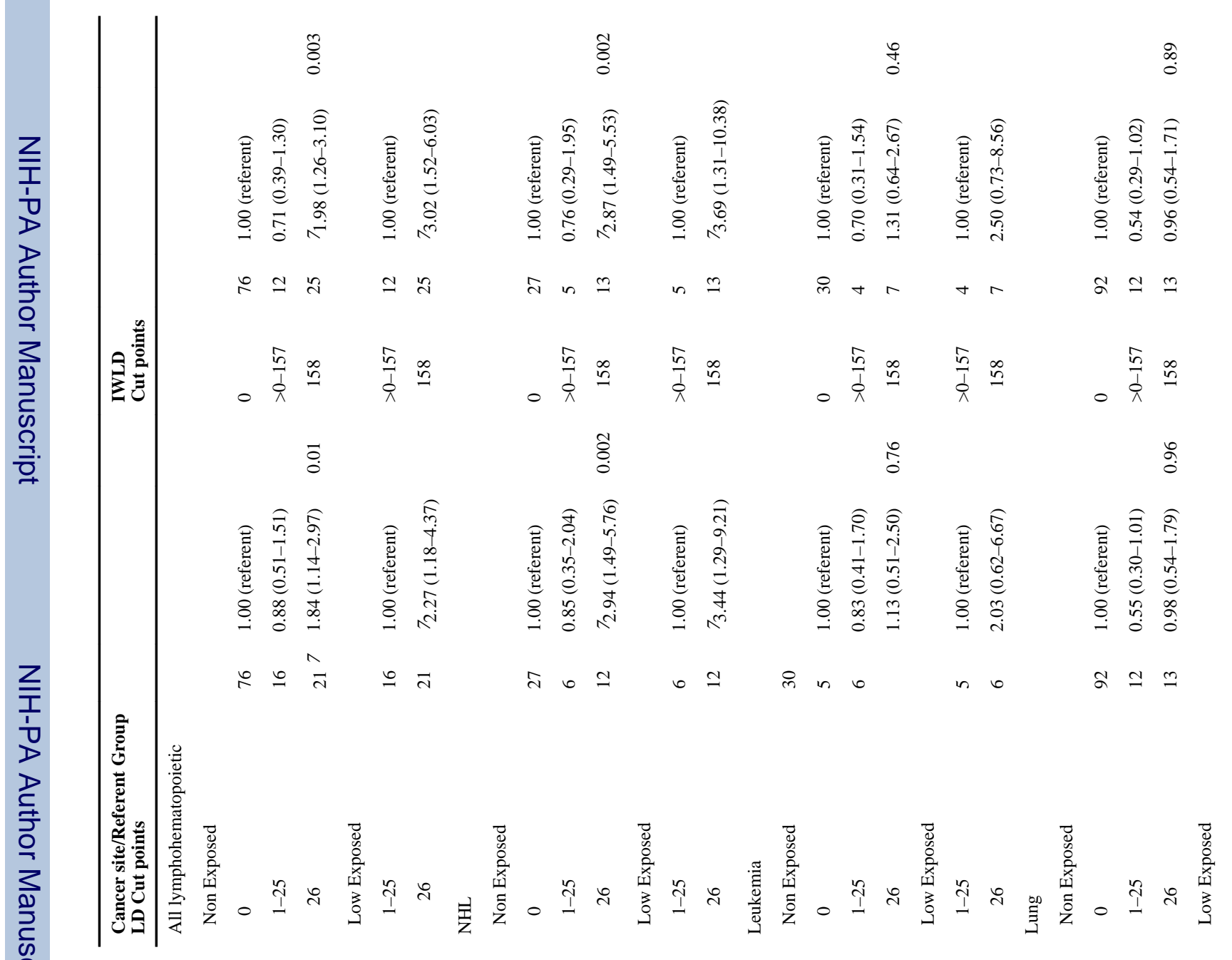




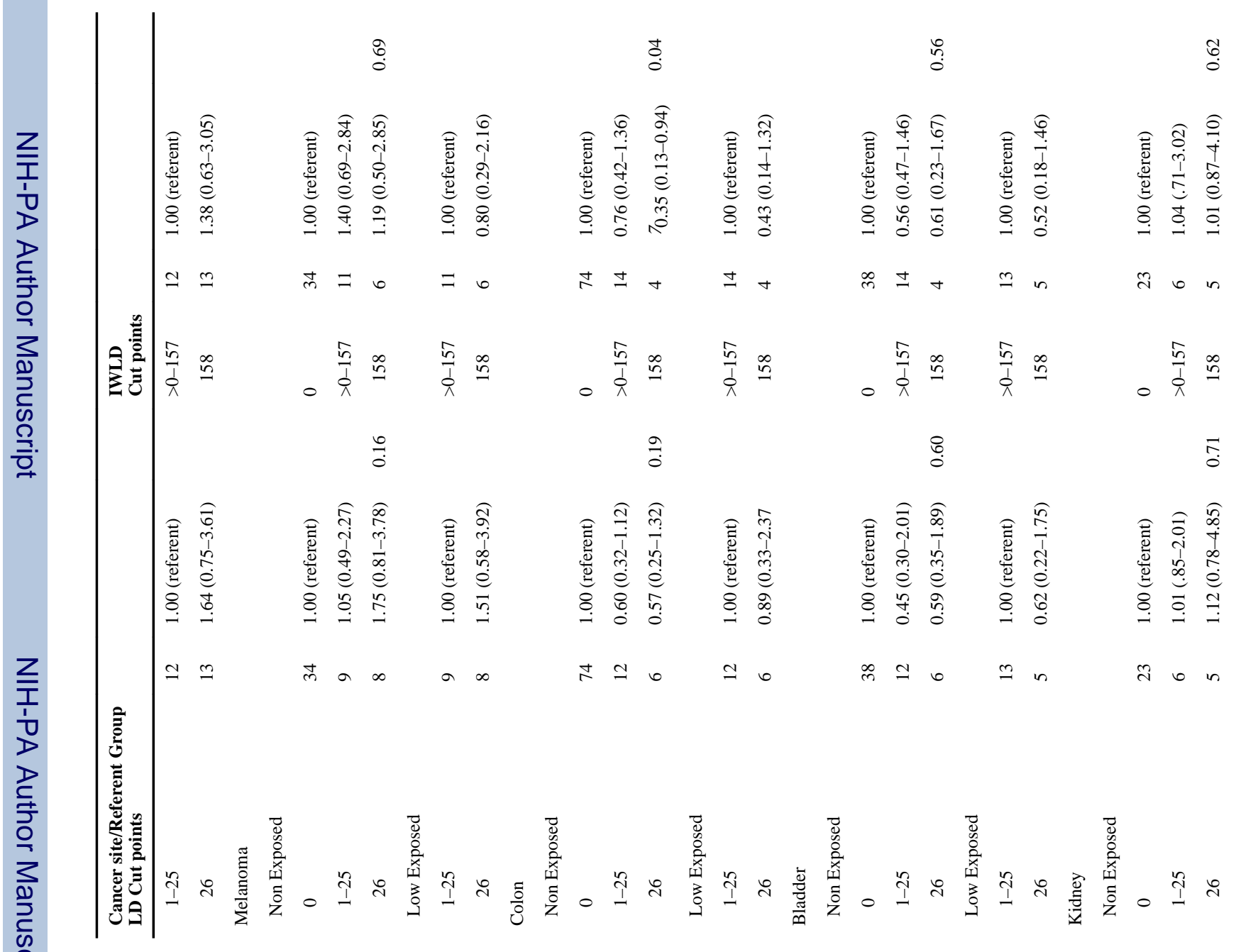




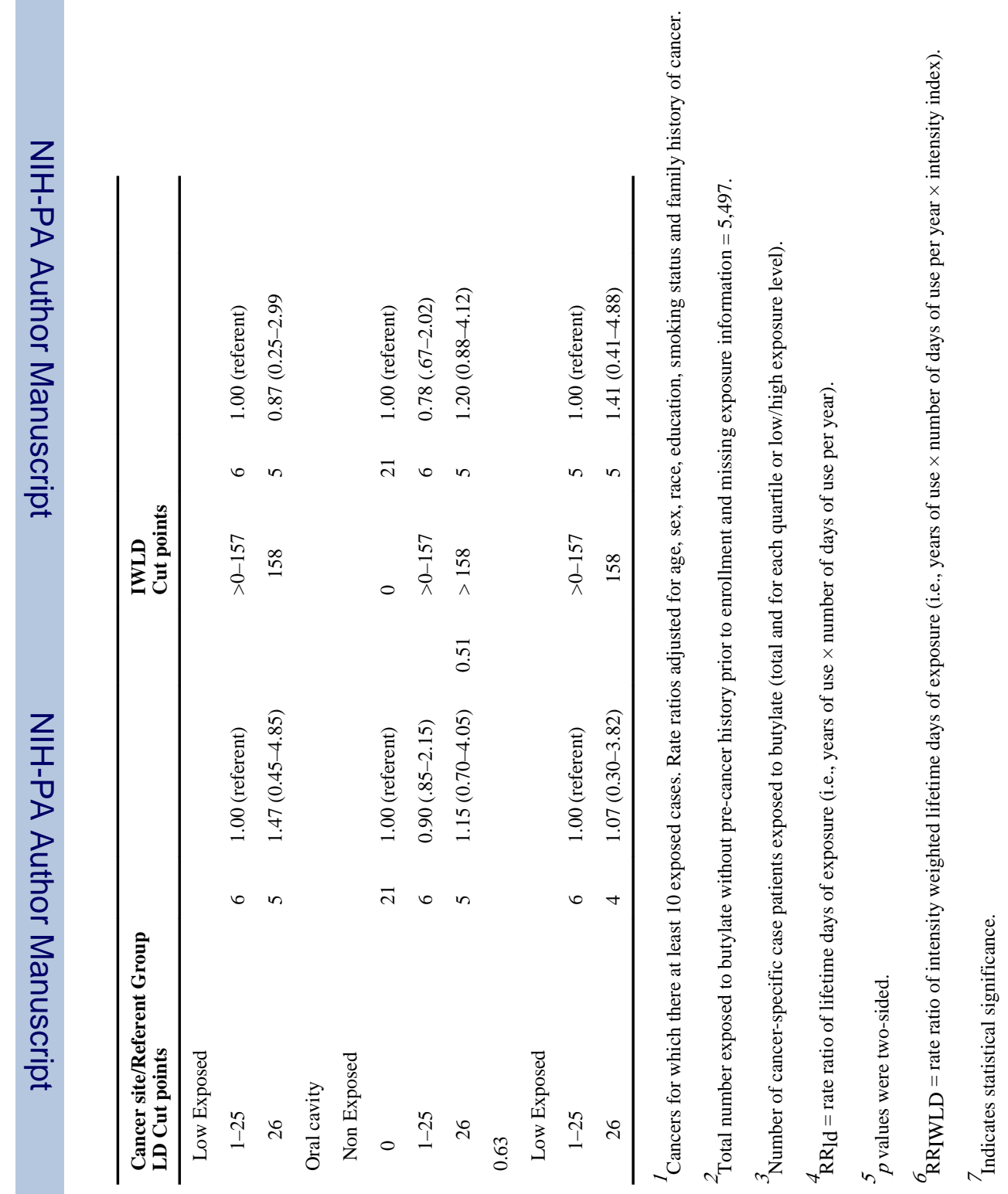

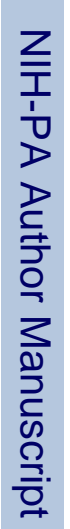




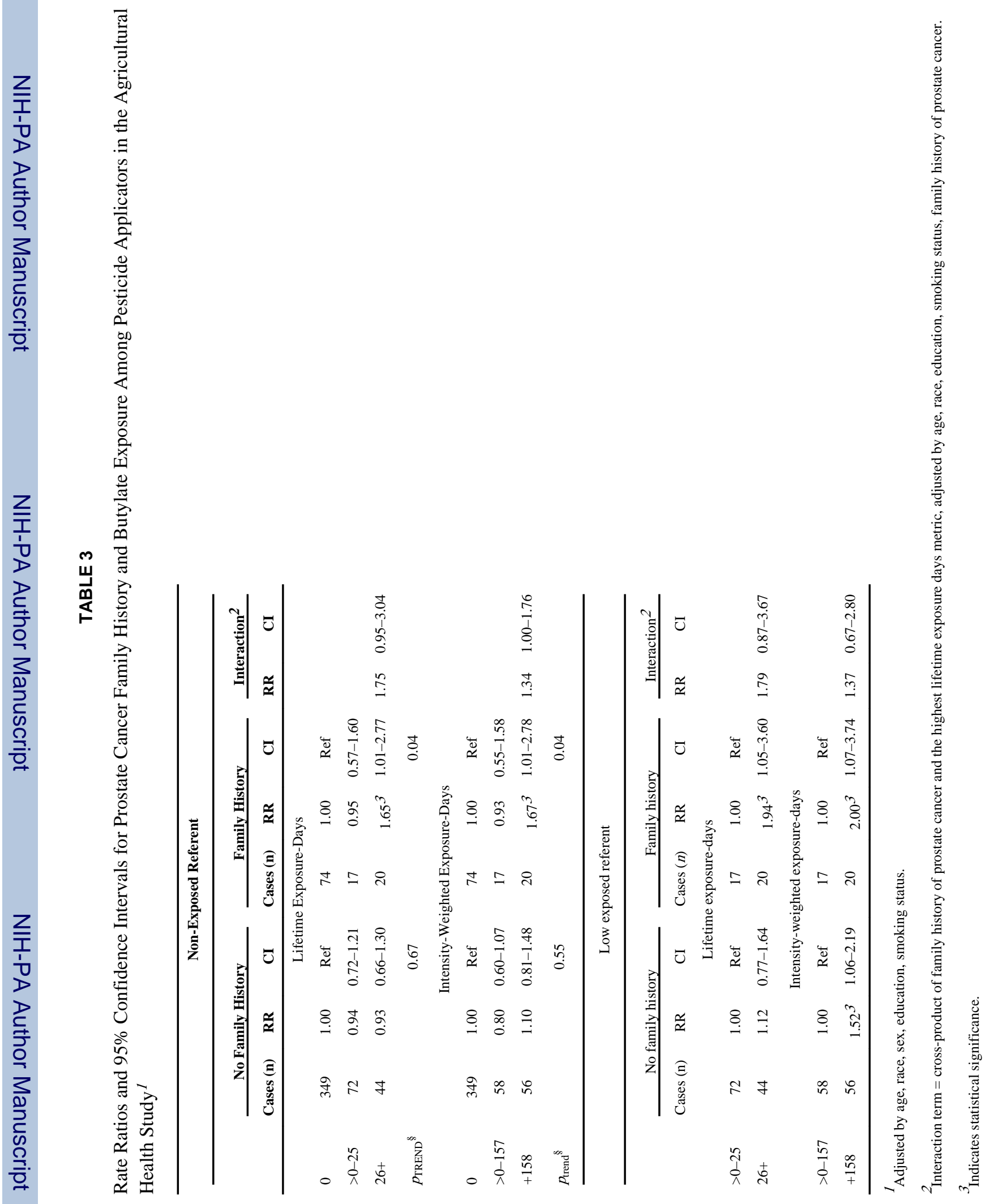

